\title{
Micro-lecture Design \& Practice in Marine Engineering English Teaching in Higher Vocational Colleges*
}

\author{
Yanli Zhu \\ Department of English \\ Qingdao Ocean Shipping Mariners College \\ Qingdao, China
}

\begin{abstract}
Micro-lecture is "short, small, refined, and effective". Marine Engineering English is an ESP which is a headache for the higher vocational college students. This paper tries to apply micro-lecture to the Marine Engineering English teaching from the point of its design and practice to activate the students' content and linguistic schemata, arouse the students' learning interest and motivation by having the students to learn at their own pace after class to satisfy their individual learning need.
\end{abstract}

Keywords-micro-lecture; marine engineering English; individual learning need; learning motivation

\section{INTRODUCTION}

The accelerated development of informatization has promoted the micro- era's coming. The micro-lecture which explains single knowledge point with the short teaching videos attracts the attention of the educational field with its unique charm [1]. Marine Engineering English is an ESP used in the engineering department on board ship, which is also an important course for engineering management major. There is no result when the author retrieved on www.CNKI.net with the theme "maritime English, marine engineering English" and "micro-lecture" with no limitation on the retrieval time, indicating that until now the research on micro-lecture of marine engineering English has not yet been fully developed. Meanwhile, it is surveyed that the development of marine Engineering English micro-lecture is still a blank in our domestic maritime colleges and universities. This study tries to innovate the teaching method of Marine Engineering English with the aid of micro-lecture from the point of design and practice, adapting to the students' learning needs and arousing the students' learning interest and motivation, and finally improve the effect of Marine Engineering English teaching in higher vocational college.

*This paper is sponsored by the Qingdao Ocean Shipping Mariners College (Project No. 2017-R-004)

\section{MICRO-LECTURE AND MARINE ENGINEERING ENGLISH}

\section{A. The Concept and Characteristics of Micro-lecture}

A micro-lecture, a short-recorded video lesson, which is basically in the form of short video teaching material, focusing on single, tightly defined topic (such as the focuses, difficulties, doubts, test points, etc.) and some teaching processes (such as learning activities, themes, experiments, tasks, etc.) [2]. A micro-lecture is an on-line video course resource which is designed for situational learning and can be used in a variety of ways. Thus, the micro-lecture possesses the following characteristics:

Firstly, the form of micro-lecture is basically micro teaching video which is as short as about 10 minutes, during which period; the students' attention is the most concentrated.

Secondly, the theme is clear. The video mainly focuses on the difficult points, with its design and construction to meet the learners' psychological need. Thus, the theme of learning is distinctive and learning focus is also more prominent. In this way, the teaching pertinence and effectiveness will be enhanced, facilitating the teaching objectives and teaching tasks' achievement.

Thirdly, micro-lecture can be in various forms, not only limited to video. At present, the form of micro-lecture is mainly based on modern educational technology, giving full play to the picture, audio, word software and so on. By diversifying the teaching practice form of micro-lecture, the knowledge will be transferred to the students through the most popular way.

Fourthly, the design is of integrity and comprehensiveness. Although micro-lecture shows a knowledge point in a course, it is not a simple cutting of the content. It requires clear teaching objectives, teaching methods and after-class exercises and etc.

Lastly, the usage of micro-lecture is flexible and convenient. The micro-lecture can be used during class teaching, and also in the autonomous learning before class and after class since its usage is not limited by time or space. 
Moreover, micro-lecture can be learned by the students at their own pace again and again through the multimedia terminal, and also can be shared to attain a good effect [2][3].

\section{B. The Characteristics of Marine Engineering English in Higher Vocational Maritime College}

Marine Engineering English is a course which aims to cultivate students' professional English application ability which is important for their future safe and efficient work on board ship to communicate with the crew, agents, shipchandlers, PSC officers, surveyors and etc. from different countries. The Marine Engineering English and its learners in Higher Vocational Maritime College respectively have the following characteristics:

On one hand, the content of Marine Engineering English covers all aspects of seafarers' working and living, including main engine, auxiliary machinery, electrical appliances, automation, marine engineering management, international conventions and etc. which are massive and complicated.

As an ESP, Marine Engineering English has its own characteristics in vocabulary, syntax, grammar, etc. which put forward a high requirement for the learners English ability.

In order to get the qualification certificate for the future job, the students are required to pass the national seafarers' English competency assessment which puts forward a high standard for the would-be seafarers to achieve effective communication on board ship according to Manila amendment of STCW. If the students do not pass the assessment, they are not qualified for the work on board ship.

On the other hand, the students entered the higher vocational college with a comparatively lower score in the college entrance examination about $180-440$ grades. In the meantime, the English ability of current Marine Engineering English learners in Higher Vocational Maritime Colleges is poor [4], [5]. Take the students' college entrance examination (perfect score 150) of the author's college in the last two years $(2015,2016)$ as an example, which is shown in "Table I", the students' score above 90 points only takes up less than $10 \%$, while a large number of students get 60 points to 89 points, and the students whose score are even less than 60 points accounts for almost 30\%. After three-term learning of college English, the percentage of the students who passed the CET 4 is no more than 5\%. Thus, we can conclude that the students' English learning ability is far from the requirements of the Marine Engineering English. With a questionnaire survey of the students, the author found that some students can hardly catch up with the teacher's pace and even though they could understand the teaching content in traditional regular class, the content will be forgotten after a short while.

TABLE I. STUDENTS' COLLEGE ENTRANCE EXAMINATION SCORE IN THE LAST TwO YEARS (2015 AND 2016)

\begin{tabular}{|c|c|c|c|c|c|}
\hline $\begin{array}{c}\text { Score (total score } \\
\text { 150) }\end{array}$ & $\mathbf{> 9 0}$ & $\mathbf{8 0 - 8 9}$ & $\mathbf{7 0 - 7 9}$ & $\mathbf{6 0 - 6 9}$ & $<\mathbf{6 0}$ \\
\hline Percentage (\%) & 8.81 & 12.09 & 13.06 & 36.72 & 29.32 \\
\hline
\end{tabular}

In order to help the students to learn Marine Engineering English effectively, encourage a self-directed model of learning, allowing students to select lessons to watch and to move through them at their own pace, make the students more concentrated during learning, make the learning objective much easier to be attained, let the students find the sense of achievement rather than frustration during learning process, we should try to introduce micro-lecture into our traditional Marine Engineering English teaching process.

\section{DESIGN PRINCIPLE OF MICRO-LECTURE}

\section{A. Carefully Selected Content to Activate Learner's Motivation}

The distinctive feature of micro-lecture is short, but the production is not simple. The teaching content in microlecture should be independent, typical and common. There should be only one knowledge point presented in one microlecture.

Since the criteria for judging the teaching effect of Marine Engineering English is the National seafarers' English competency assessment, the micro-lecture should focus on the emphasis, difficult points and test points of this course to help the students pass the examination and gain the certificate for their future job.

The micro-lecture is exam-directed and aimed at the difficult points from the standpoint of the learner; the students' learning motivation will be activated since the certificate is a must for their profession development. The individualized learning based on students' different knowledge defects can be realized, improving their learning freedom and enhancing their self-confidence [6].

\section{B. Practical Teaching Design to Satisfy the Learner's Need}

Reasonable and effective teaching content design can draw teachers and students closer, and attract more students to participate in learning. The purpose of the micro-lecture for Marine Engineering English is to help the students grasp the content of this course and finally gain the certificate, not for attending micro-lecture teaching contest, thus the microlecture production is not necessarily "delicate, expensive, time-consuming". As long as the form of expression is appropriate and accepted by the students, it is practical [7].

In order to satisfy the need of the students, a questionnaire survey to investigate the students' need of learning prior to the micro-lecture's designing should be conducted to clarify the difficult points during the students' learning of Marine Engineering English, the micro-lecture form the students need, the language preferred by the students and so on. The micro-lecture produced in this way would be practical, effective and suitable for the students' learning.

Since the production of such practical micro-lecture is comparatively easier to handle for the front-line teachers, much cheaper, more time-saving, and meanwhile it is as effective and popular as the "delicate, expensive, timeconsuming" micro-lecture, a large number of such micro- 
lecture would be produced and utilized in our daily teaching process.

\section{Abundant Supporting Resources for Micro-lecture}

From the students' standpoint, micro-lecture mainly has the following functions: one is for daily teaching combined with the flip classroom teaching mode, the other is a way to facilitate students' autonomous learning.

In order to achieve either of these two functions, abundant supporting resources are needed. Whether the micro-lecture is impressive to the students and the teaching aim would be attained or not is not only depends on the content integrity, design attraction, but also the wonderful learning experience for the learners. Exercises, homework, feedback, discussion, quiz, answering the questions related to the micro-lecture and some other kinds of resources can effectively facilitate their learning, activate and inspire the learners' thinking, improve the learners' understanding of the knowledge, establish the learning community of the learners and teachers, make learning process more humanized [8]. According to the survey, more than $85 \%$ of the students wish to have the relevant supporting resources and believe the micro-lecture related test would activate their learning motivation and benefit their learning.

If the micro-lecture is utilized without any supporting resources will make the micro-lecture isolated, the knowledge fragmental, not conducive to the students' learning, and the efficiency of micro-lecture will be greatly reduced. Based on the "very 6+1" [9] of Tiesheng Hu and the survey of the students, the supporting resources for the micro-lecture could include the followings:

- Teaching design to clarify the teaching tasks, present the detailed teaching arrangement;

- Task list of micro-lecture to conduct the students' learning to improve the learning effectiveness;

- Relevant exercises to consolidate the knowledge learned in the micro-lecture;

- Analysis for the related knowledge which is a proofreading and explanation for the exercises to find out the weakness and widening the idea of solving the problem;

- Related courseware, such as lecture notes, ppt and so on;

- Test for checking the learning situation and promoting the students' learning efficiency;

- Related extension knowledge to guide the wider and deeper learning and avoid the fragmentation of the knowledge [8].

\section{PRACTICE OF MiCRO-LECTURE IN MARINE}

ENGINEERING ENGLISH TEACHING IN HIGHER VOCATIONAL COLLEGE

When introducing the micro-lecture to the Marine Engineering English Teaching in higher vocational college, we should pay attention to the combination of the microlecture and the realistic class. We could apply different kinds of micro-lecture design and strategy according to different purposes based on the realistic classroom teaching. As to the Marine Engineering English Teaching in higher vocational college, the application of micro-lecture will be focused on the pre-class and post-class stages.

\section{A. Pre-class Stage}

Good preparation before class is one of the most important procedures to help the students to master knowledge as soon as possible. Since Marine Engineering English is an ESP which is highly professional in both content and language, the pre-class micro-lecture of Marine Engineering English should focus on activating the students' content schemata which has been learned in their professional course but may be forgotten, and constructing their linguistic schemata such as technical terms, sentence structure and so on. Thus, the students will get ready for the coming knowledge psychologically, their desire for the new knowledge will be stimulated, the obstacles of Marine Engineering English learning will be greatly reduced, and the students will become active learners rather than passive ones. Good preparation before class can help the students to figure out the difficulties and important points, arouse the students' curiosity and interest, and improve the students' learning motivation. In the meanwhile, good preparation will make the students' learning more targeted; improve the efficiency of class learning especially for these students with learning obstacles.

At the same time, the interaction between the teacher and the students outside the classroom will draw them much closer emotionally, the feedback from the students will facilitate the teacher to be clear of the students' learning weaknesses and difficulties, the teaching activities in realistic class based on the feedback of pre-class will be more focused and targeted.

In higher vocational college, the students often experience the frustration rather than fulfillment, their learning initiative is comparatively poor, in order to arouse the students' interest and motivation, we should pay much attention to adapt the difficulty of the task to be a little bit higher than the students' ability according to " $i+1$ " principle and try every effort to make the micro-lecture interesting and refined. Since one of the purposes of the pre-class microlecture is to activate the students' content schemata, the content of the micro-lecture should be carefully selected, directly related or indirectly related to the coming knowledge, neither too easy nor too difficult. Organize some cooperative activities to have the students to find out the text-related professional content by themselves before class and produce their own micro-lecture could also be helpful. As to the linguistic schema activation, we need to consider the students' previous English capability, to make the form of the micro-lecture more attractive and approachable, using group work of competition, game and so on. 


\section{B. Post-class Stage}

Application of micro-lecture during the post-class stage could be quite effective to help the students review and understand the difficult points and focus of the lesson, to consolidate what they have learned in class and ultimately to improve their learning effectiveness.

Teachers could produce the micro-lecture by summing the key points up by using the pictures, animations, videos and etc. It is convenient for the students to review the knowledge by themselves at their own pace with purpose after class. As for the simple knowledge, the students can look through it quickly while as for the emphasis and difficulty, the students can watch the video repeatedly. The content of such micro-lecture should be rich, which can be divided into several units according to the degree of difficulty to meet the needs of the students of different levels. But due to the nature of the micro-lecture, the content in each micro-lecture should be restricted to make the micro-lecture short and refined.

Teachers can also produce the micro-lecture specifically designed for explaining the difficult points, such as a common mistake, typical questions, sentence structure analysis, and grammar difficulties and so on. The microlecture could explain the questions in detail, helping the students to understand the difficulties, to summarize and reflect on what they learned in class.

Since the students are required to pass the national seafarers' English competency assessment in the end of this course to attain the certificate to work on board ship, in daily teaching we should pay much attention to improve students' learning with some tests which will also improve their learning motivation. For this purpose, we need to develop electronic exercise bank and test-online system as supporting resources, which can be used combining with the microlecture to facilitate the after-class quiz and unit test to check the learning effect, so as to stimulate the students' learning motivation and interest.

At the same time, the online teaching platform can be used to record and preserve students' learning footprints and record the students' evaluation and feedback to help students to understand their own learning situation. It can also be used for teachers to collect and analyze the teaching effect and students' learning situation, to facilitate teachers to help students to make their individualized learning plan, to make formative assessment of students by considering the performance before and after class on line, and to urge students to pay much attention to their learning process and achieve effective learning.

\section{CONCLUSION}

Marine Engineering English is an ESP which has its own characteristics in both content and language, while the English capability of the students in higher vocational college is far from the requirements; traditional class teaching can hardly help the students to meet the requirements of the national seafarers' English competency assessment. Introducing the micro-lecture to the traditional
Marine Engineering English teaching would be helpful in activating the students' content and linguistic schemata before class and allowing students to learn at their own pace after class to understand and consolidate the knowledge. With micro-lecture on line, the students' learning process could be easily monitored, their learning motivation will be improved since individualized learning is encouraged and interaction between teacher and students is much closer, and finally their learning effectiveness will be enhanced to help the students achieve their learning objectives.

\section{REFERENCES}

[1] Xiaohua Dai, Chen Lin. Research on the status and optimization Strategy of micro-lecture in Chinese primary and secondary schools [J]. China Educational Technology, 2014 (9): 78-83.

[2] Wang Feng. Research on the application of micro-lecture to college English teaching[J]. Theory and Practice of Education, 2016 (27) 4748.

[3] Xia Jijun. The problem, reason and ways of micro-lecture teaching in higher vocational college [J]. Education and Vocation, 2017(19)89-92.

[4] Xu Yao-sheng. The situation of students in higher vocational colleges and the countermeasures to solve the dilemma[J]. Vocational \& Technical Education Forum, 2011(29):94-96.

[5] Dong Zhen-wen. Problems and countermeasures of students' quality in higher vocational college [J]. China Adult Education, 2007(1): 112.

[6] Liu Hongxia, Zhao Wei, Chen Lei. An empirical reflection and design on teaching behaviors based on the ontological characteristics of the micro-lecture[J]. Modern Educational Technology, 2014(2)1419.

[7] Yu Shengquan, Chen Min. Design of micro-lecture based on learning cell system[J]. Open Education Research. 2014(2) 100-110.

[8] Zhou Xianbo. The study on the construction strategies of microLectures based on the learners' perspective[J]. China Educational Technology, 2015(4) 81-90.

[9] $\mathrm{Hu}$ Tiesheng. Analysis on the difficulties in the construction and application of micro-lecture in primary and middle schools[J]. Primary and Middle School Information technology education, 2013(4)15-18. 